\title{
PENGARUH TEKSTUR PERMUKAAN MATERIAL UHMWPE TERHADAP DISTRIBUSI TEGANGAN PADA BEBAN KONTAK STATIC, ROLLING DAN SLIDING
}

\author{
*Jamari, F.H. Priyoga \\ Laboratorium Perancangan Teknik dan Tribologi \\ Departemen Teknik Mesin, Fakultas Teknik, Universitas Diponegoro \\ Jl. Prof. Soedarto SH, Tembalang, Semarang 50275 Indonesi Telp/Fax: +62 247460059 \\ *E-mail: j.jamari@gmail.com
}

\begin{abstract}
ABSTRAK
Material UHMWPE (Ultra High Molecular Weight Polyethylene) sering digunakan sebagai actebular liner pada sistem sambungan tulang panggul buatan. Fungsi material ini sebagai bantalan dan peredam. Performansi material ini terus dikaji dan ditingkatkan melalui berbagai macam teknologi. Optimasi bentuk tekstur merupakan salah satu cara dalam meningkatkan karakteristik tribologi. Paper ini bertujuan mengkaji pengaruh tekstur permukaan terhadap distribusi tegangan von Mises untuk beban statik, roling dan sliding. Perhitungan tegangan dan distribusinya dilakukan mengunakan metode elemen hingga. Hasil menunjukkan bahwa untuk semua kasus pembebanan baik statik, roling maupun sliding tegangan von Mises yang terbesar terjadi pada tekstur permukaan yang memiliki diameter lubang (cavities) yang terkecil. Selain itu besarnya tegangan maksimum von Mises paling besar terjadi pada kasus beban kontak sliding kemudian kontak roling dan yang paling kecil kontak statik.
\end{abstract}

Kata kunci: UHMWPE, tekstur permukaan, mekanika kontak, metode elemen hingga.

\section{PENDAHULUAN}

Sendi panggul buatan atau artificial hip joint (AHJ) merupakan salah satu prosthesis yang telah dikembangkan oleh Departemen Teknik Mesin Undip bersama dengan RS Ortopedi Soeharso Solo. Komponen AHJ dapat dibagi menjadi dua, yaitu komponen acetabular dan komponen femoral [1]. Komponen acetabular terdiri dari acetabular shell dan acetabular liner, sedangkan komponen femoral terdiri dari femoral head dan femoral stem. Acetabular shell adalah bagian terluar dari AHJ dan juga sebagai mangkok logam yang ditanam ke acetabulum (tulang pelvis). Acetabular liner yang menempel pada komponen acetabular shell memiliki fungsi sebagai bearing pada kontak dengan femoral head. Femoral head ditanam sebagai pengganti tulang kepala femur dimana kepala femur asli telah dinyatakan tidak bekerja dengan baik yang dikarenakan oleh beberapa alasan. Femoral stem ditanam pada tulang paha sebagai penguat dan fiksasi produk AHJ agar memiliki ikatan. Berdasarkan data di RSO dr. Soeharso, bahan yang banyak paling banyak digunakan untuk acetabular liner adalah UHMWPE (Ultra High Molecular Weight Polyethylene) sedangkan untuk acetabular shell, femoral head dan femoral stem terbuat dari material stainless steel AISI 316L [2]. Kombinasi polymer dengan metal juga telah teruji dan memiliki sifat keausan yang lebih baik dibanding jenis metal dengan metal [3].

Prototipe produk sendi panggul buatan Undip-RSO Soeharso juga menggunakan logam dan polimer. Bahan logam yang digunakan adalah AISI 316L yang digunakan pada komponen femoral stem, femoral head dan acetabular shell. Sedangkan bahan polimer yang digunakan adalah UHMWPE yang digunakan pada acetabular liner yang berfungsi sebagai bantalan atau bearing, peredam getaran dan impak atau shock absorber. Pada AHJ keausan merupakan parameter yang sangat menentukan. Parameter keausan yang berpengaruh adalah: beban, luas kontak area, contact pressure dan material yang mengalami kontak. Contact pressure sangat dipengaruhi oleh tekstur permukaan yang berkontak. Selain itu, ketebalan acetabular liner juga dipandang berpengaruh terhadap parameter keausan [4-6]. Penelitian tentang AHJ senantiasa selalu berkembang demi memperoleh karakteristik performansi yang maksimal. Salah satunya adalah perancangan tekstur permukaan AHJ dengan bentuk tertentu yang dapat mengurangi tegangan kontak dan meningkatkan efek pelumasan [7, 8].

Paper ini bertujuan mengkaji pengaruh tekstur permukaan terhadap distribusi tegangan von Mises untuk beban statik, roling dan sliding. Beberapa tekstur permukaan divariasikan dengan parameter jarak antar lubang (cavities) dan parameter diameter lubang. Perhitungan tegangan dan distribusinya dilakukan mengunakan metode elemen hingga [9]. Pembebanan rolling dan sliding menggunakan metode seperti yang telah dikembangkan sebelumnya pada $[10,11]$.

\section{MATERIAL DAN METODOLOGI}

Pada penelitian ini, hasil penelitian Lopez dkk. [7,8] dijadikan rujukan utama. Hasil penelitian mereka akan dibandingkan dengan hasil penelitian yang dilakukan. Penelitian mereka hanya terbatas pada beban statik, sedangkan pada penelitian ini menggunakan beban statik, rolling dan sliding. Hal ini karena pada kontak AHJ 
ketiga jenis pembebanan tersebut sering terjadi akibat pasien yang selalu bergerak.

Jenis material UHMWPE yang digunakan Lopez dkk. [7,8] juga digunakan pada penelitian ini. Modulus elastisitas material ini adalah $945 \mathrm{MPa}$ dengan rasio Poisson 0.46. Data material ini akan diinputkan pada model elemen hingga yang dibangun. Perangkat lunak komersial untuk analisa metode elemen hingga ABAQUS digunakan untuk mensimulasikan proses pembebanan kontak dan menghitung tegangan-tegangan yang terjadi selama penelitian ini. Gambar 1 menunjukkan model elemen hingga tiga dimensi (3D) material UHMWPE yang mampu berdeformasi (deformable). $S$ merupakan jarak antar lubang secara vertikal dan secara horizontal. $D$ adalah diameter lubang silider atau cavity. Parameter $D$ ini akan divariasi dengan mempertahankan dimensi pelat UHMWPE. Dengan demikian, bila $S$ dan $D$ semakin kecil maka jumlah lubang silinder akan semakin banyak, dan sebaliknya. Lubang-lubang silinder ini akan berfungsi sebagai tempat penyimpanan pelumas.
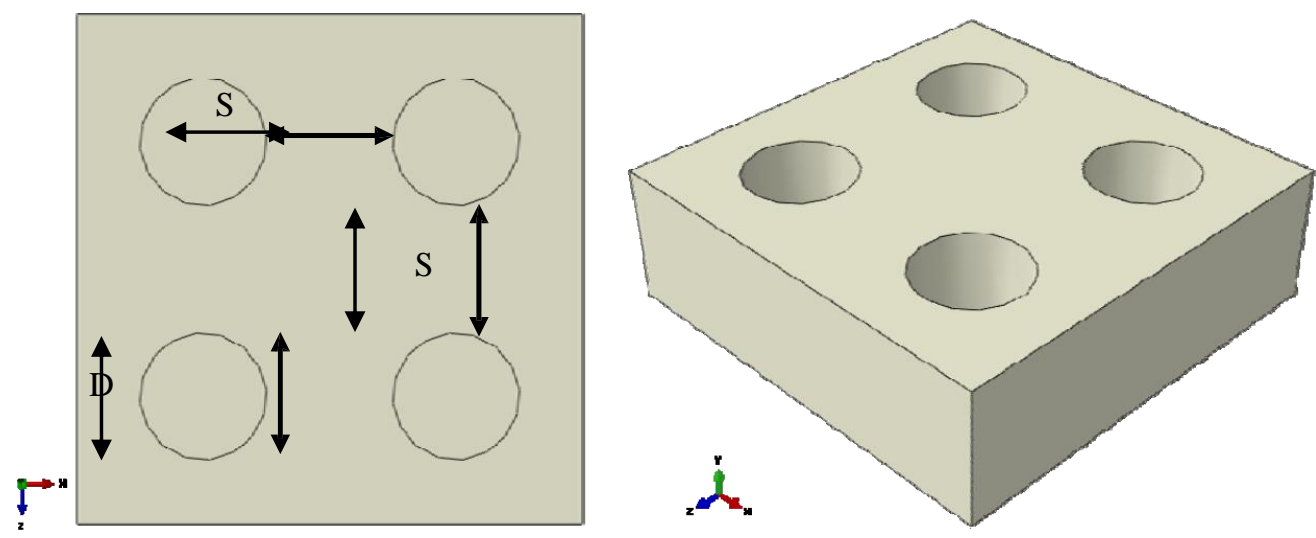

Gambar 1. Model 3D material UHMWPE dengan variasi diameter lubang dan jarak antar lubang.

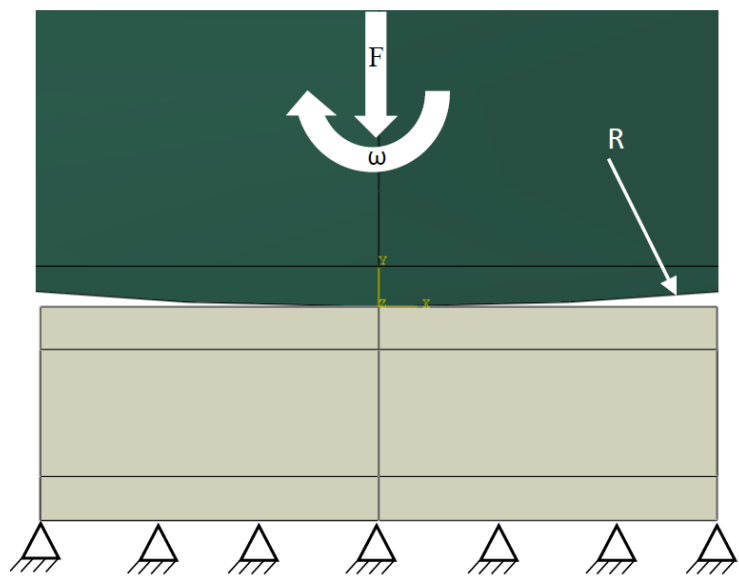

Gambar 2. Model elemen hingga untuk kontak 3D antara bola rigid dengan material UHMWPE yang mampu deformasi.

Secara umum metodologi yang digunakan pada analisa elemen hingga ini serupa dengan prosedur pemodelan yang telah dilakukan oleh Jamari [9]. Pemecahan masalah terdiri dari: Pre-Processing (Part, Property dan Assembly), Solution (Step, Interaction, Load dan Mesh) dan Post-Processing (Job dan Visualization). Untuk pemodelan beban kontak sliding dan beban kontak roling mengacu pada penelitian yang pernah dilakukan sebelumnya yaitu pemodelan sliding [10] dan pemodelan roling [11].

Gambar 2 menjelaskan lebih detail model 3D elemen hingga yang dibangun. Semua kondisi batas dideskripsikan di gambar ini. Semua nodal pada bagian bawah pelat UHMWPE ditahan agar tidak bergerak ke segala arah. Sebuah bola baja dengan radius $R$ yang rigid atau tidak berdeformasi dikontakkan secara statik dari atasnya dengan beban $F$. Pada penelitian ini digunakan radius bola baja $R=9.525 \mathrm{~mm}$ dan beban $F=17 \mathrm{~N}$. Jenis elemen hingga yang digunakan adalah tipe C3D8R. Jumlah elemen tergantung oleh nilai variasi $S$ dan $D$. Beban sliding dilakukan dengan melakukan beban statik kemudian digeser atau digerakkan tanpa memutarnya. $\square$ di sini merupakan simbol bahwa benda tersebut dikenakan beban roling atau diputar. 


\section{HASIL-HASIL DAN PEMBAHASAN}

Gambar 3 menunjukkan hasil simulasi beban statik untuk kelima variasi diameter cavities $D$ yang berbeda-beda. Kontur warna pada gambar tersebut merepresentasikan distribusi tegangan von Mises yang terjadi akibat beban kontak. Warna merah menunjukkan tegangan yang paling maksimum. Dapat dilihat dari kelima hasil-hasil tersebut bahwa diameter cavities terkecil memiliki tegangan von Mises maksimal dan sebaliknya diameter cavities terbesar memiliki tegangan von Mises terkecil. Hasil ini cukup baik dan sangat logis karena pada kondisi dimana diameter cavities yang semakin kecil maka jumlah cavities akan semakin banyak yang pada gilirannya akan mengurangi luas permukaan kontak. Dengan beban yang sama maka tegangan yang terjadi akan semakin besar apabila dikontakkan dengan benda yang memiliki luas permukaan kontak yang lebih kecil dibandingkan dengan benda yang memiliki luas permukaan kontak yang besar.

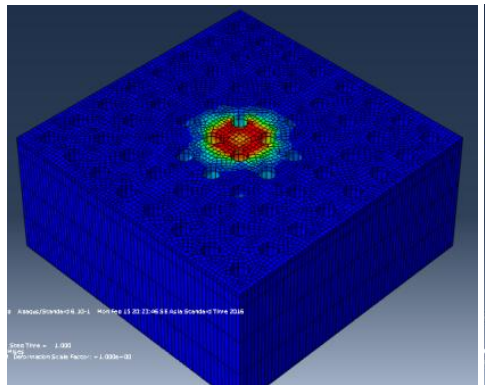

a) $D=0.397 \mathrm{~mm}$

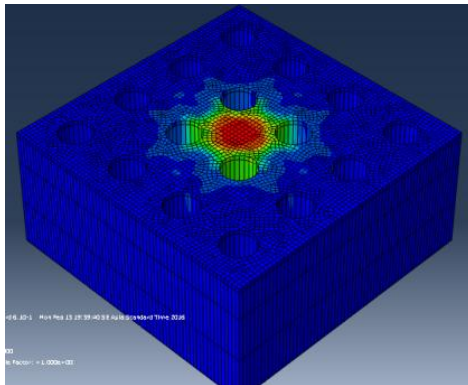

b) $D=0.794 \mathrm{~mm}$

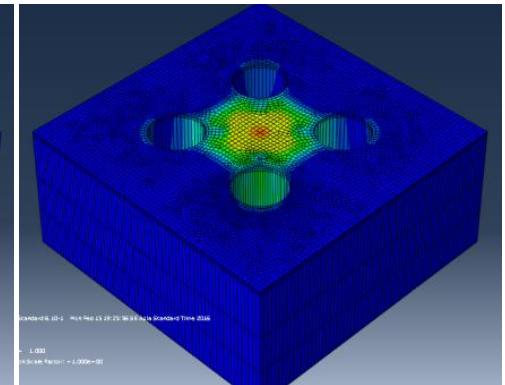

c) $D=1.191 \mathrm{~mm}$

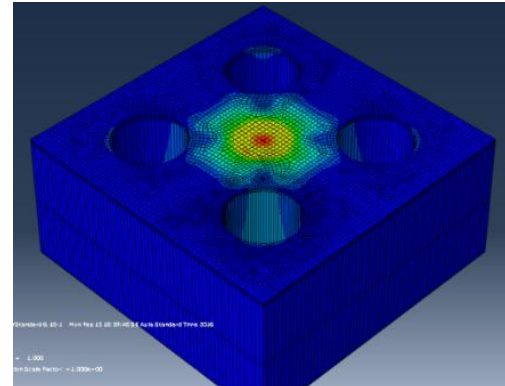

d) $D=1.588 \mathrm{~mm}$

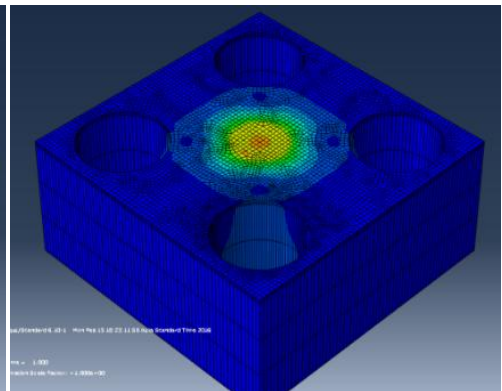

e) $D=1.985 \mathrm{~mm}$

Gambar 3. Hasil simulasi static contact dengan variasi diameter cavities.

Hasil simulasi kontak UHMWPE yang bertekstur akibat beban sliding ditunjukkan pada Gambar 4. Pada kontak sliding menghasilkan fenomena cukup menarik. Sama dengan kasus beban static, pada beban kontak sliding semakin besar diameter cavities semakin rendah tegangan von Mises maksimum yang dihasilkan. Yang menarik adalah pada beban sliding tegangan maksimum terjadi pada jarak sliding yang semakin tinggi. Hal ini dikarenakan akumulasi flow stress selama proses sliding. Pelebaran distribusi tegangan tidak dikarenakan jarak sliding melainkan akibat kondisi cavities saat dimulainya kontak.

Gambar 5 menampilkan hasil simulasi metode elemen hingga pada kontak roling. Hasil simulasi kontak rolling masih mirip dengan kasus kontak statik dan kontak sliding, dimana tegangan von Mises maksimum terjadi pada diameter cavities yang semakin kecil. Fenomena distribusi tegangan juga mirip dengan kasus kontak sliding, hanya pada kasus kontak roling tegangan maksimum yang terjadi masih di bawah kontak sliding dan di atas kontak statik. Flow stess yang mengakibatnya terjadinya fenomena ini. Gesekan pada kontak roling relatif sangat kecil dibandingkan dengan gesekan saat kontak sliding.

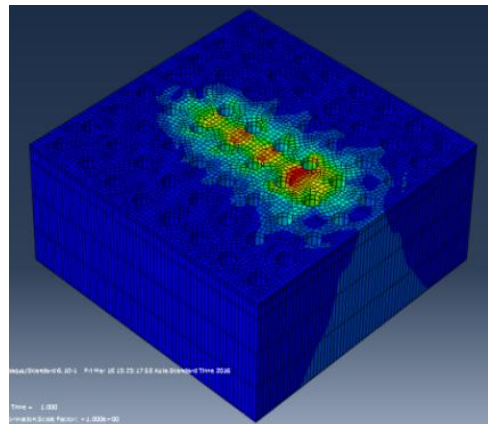

a) $D=0.397 \mathrm{~mm}$

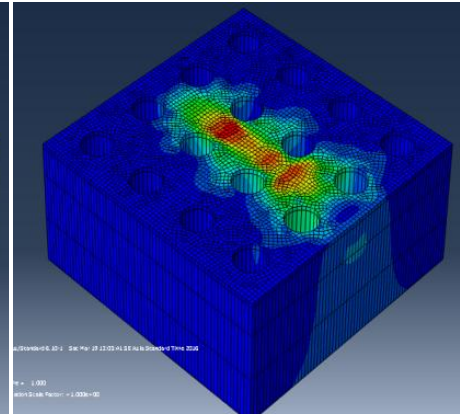

b) $D=0.794 \mathrm{~mm}$

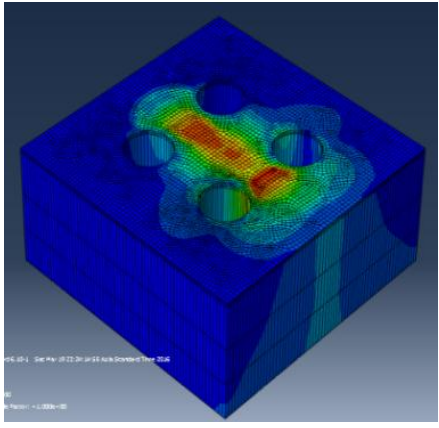

c) $D=1.191 \mathrm{~mm}$ 


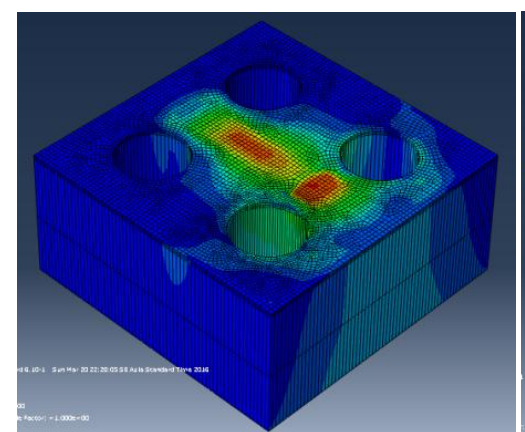

d) $D=1.588 \mathrm{~mm}$

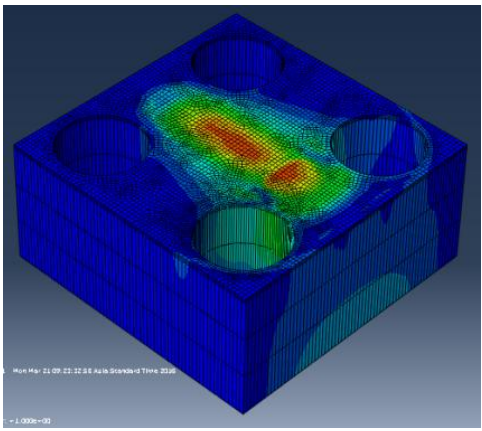

e) $D=1.191 \mathrm{~mm}$

Gambar 4. Hasil simulasi sliding contact dengan variasi diameter cavities.

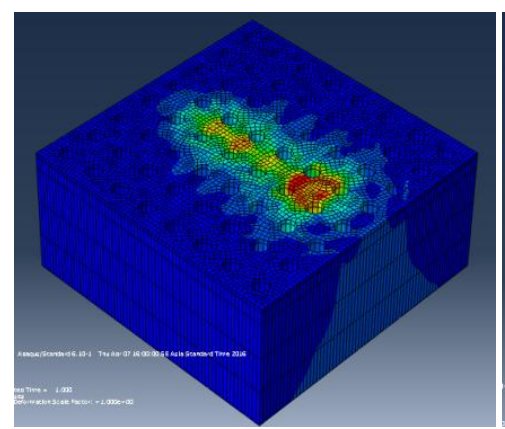

a) $D=0.397 \mathrm{~mm}$

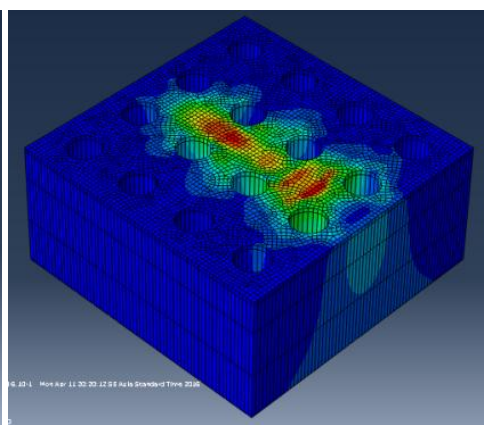

b) $D=0.794 \mathrm{~mm}$

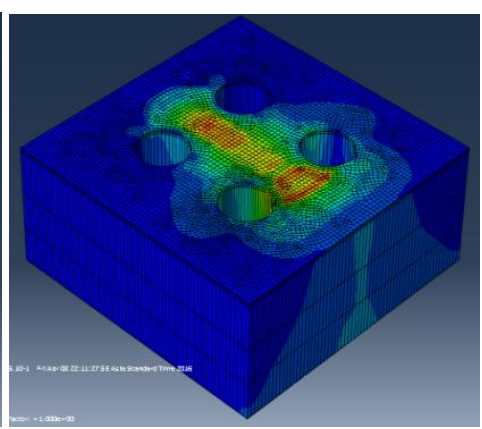

c) $D=1.191 \mathrm{~mm}$

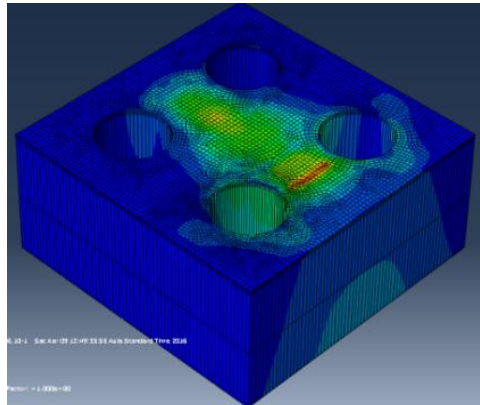

d) $D=1.588 \mathrm{~mm}$

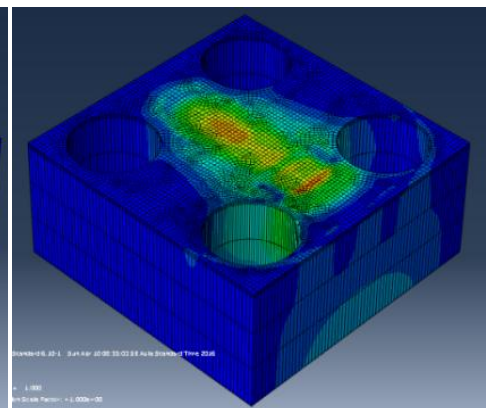

e) $D=1.985 \mathrm{~mm}$

Gambar 5. Hasil simulasi rolling contact dengan variasi diameter cavities.

\section{KESIMPULAN}

Performansi material UHMWPE yang digunakan pada acetabular liner yang berfungsi sebagai bantalan atau bearing dan peredam getaran dan impak atau shock absorber terus ditingkatkan hingga saat ini. Salah satu metode yang digunakan adalah menemukan bentuk tekstur permukaan yang memiliki karakteristik tribologi maksimal.

Kajian pengaruh beberapa tekstur permukaan terhadap distribusi tegangan von Mises untuk tiga jenis pembebanan yang berbeda yaitu statik, roling dan sliding telah dilakukan. Perhitungan tegangan dan distribusinya dilakukan mengunakan aplikasi perangkat lunak komersial berbasis metode elemen hingga ABAQUS. Pada simulasi static contact dari semua variasi diameter cavities menghasilkan nilai maksimum tegangan von Mises yang berbedabeda. Ketika diameter cavities semakin besar, maka nilai maksimum tegangan von Mises yang dihasilkan akan semakin kecil. Fenomena ini juga terjadi pada semua jenis pembebanan yang telah dilakukan. Secara keseluruhan, nilai maksimum tegangan von Mises yang dihasilkan dari simulasi sliding contact adalah yang paling tinggi, dan nilai maksimum tegangan von Mises dari simulasi static contact adalah yang paling rendah.

\section{DAFTAR PUSTAKA}

[1] Jessica, N., Soto, A., Cora, N.C., dan Irizarry, J.F., 2005, Mechanics of Biomaterials: Orthopedics, University of Puerto Rico, Mayaguez.

[2] RSO dr Soeharso, 2012, Data Rekam Medis Pasien RSO dr. Soeharso Tahun 2012, Laporan Internal Rumah Sakit, Solo.

[3] Kiefer, H., 2007, "Current trends in total hip arthroplasty in Europe and experiences with the contact hip system," in Treatment of Osteoarthritic Change in the Hip, Springer, Japan. 
[4] Saputra, E., Anwar, I.B., Jamari, J., van Der Heide, E., 2013, "Finite element analysis of artificial hip joint movement during human activities," Procedia Engineering, 68, pp. 102-108.

[5] Saputra, E., Anwar, I.B., Ismail, R., Jamari, J., van Der Heide, E., 2014, "Numerical simulation of artificial hip joint movement for Western and Japanese-style activities," Jurnal Teknologi, 66(3), pp. 53-58.

[6] Saputra, E., Anwar, I.B., Ismail, R., Jamari, J., van Der Heide, E., 2016, "Finite element analysis of the impingement on the acetabular liner rim due to wear of the acetabular liner surface," AIP Conference Proceedings, 1725, pp. 020074.

[7] Lopez-Cervantes, A., Dominguez-Lopez, I., Barceinas-Sanchez, J.D.O., Lesso-Arroyo, R., Garcia-Miranda, J.S., Garcia-Garcia, A.L., 2012, "Effects of texturing on stress distribution of a UHMWPE surface," (XVIII Congreso Internacional Anual De La Somim, Mexico 19-21 September 2012) pp. 305-312.

[8] Lopez-Cervantes, A., Dominguez-Lopez, I., Barceinas-Sanchez, J.D.O., Garcia-Garcia, A.L., 2013, "Effect of surface texturing on the performance of biocompatible UHMWPE as a bearing material during in vitro lubricated sliding/rolling motion” Journal of Mechanical Behavior of Biomedical Materials, 20, pp. 45-53.

[9] Jamari, J., 2011, “Analisa kontak statis permukaan kasar berbasis metode elemen hingga,” ROTASI, 13(2), pp. 1317.

[10] Jamari., J., 2013, "Pemodelan elemen hingga kontak sliding berulang antara bola dengan permukaan kasar," ROTASI, 15(3), pp. 14-18.

[11] Ismail, R., Saputra, E., Tauviqirrahman, M., Jamari., J., Schipper, D.J., 2013, "Modeling of repeated rolling contact on rough surface: surface topographical change," Advanced Materials Research, 896, pp. $642-645$. 